\title{
OS PRINCIPAIS ASPECTOS JURÍDICOS DO FACTORING NO DIREITO BRASILEIRO
}

\section{Elaine Cristina Pardi Domingues ${ }^{1}$}

Resumo: $O$ presente artigo tem 0 propósito de contribuir para a formação de elementos que possam caracterizar o factoring dentro de uma disciplina jurídica própria, tendo em vista que a atividade é praticada no Brasil há mais de trinta anos, mas ainda não possui uma legislação específica que regulamente as suas operações. A par disso, buscou-se analisar os principais aspectos jurídicos da operação no direito brasileiro, com o intuito de contribuir para o estudo jurídico e o aprimoramento do instituto.

Palavras-chaves: Factoring; Aspectos; Jurídicos; Direito; Brasileiro.

Abstract: This article aims to contribute to the formation of elements that can characterize factoring in a separate legal discipline, given that the activity is practiced in Brazil for over thirty years, but does not have specific legislation governing its operations. Alongside this, it sought to analyze the main legal aspects of the operation in Brazilian law, in order to contribute to the legal study and improvement of the institute.

Key words: Factoring; Aspects; Legal; Right; Brazilian.

${ }^{1}$ Doutoranda em Filosofia do Direito pela Pontifícia Universidade Católica de São Paulo - PUC/SP.
Mestra em Direito das Relações Sociais - Direito Comercial pela Pontifícia Universidade Católica de São
Paulo - PUC/SP. Especialista em Direito Empresarial pela Pontifícia Universidade Católica de São Paulo
- PUC/SP. Graduada em Direito pelas Faculdades Metropolitanas Unidas - FMU. Advogada. Professora
da Universidade Paulista - UNIP, onde leciona a matéria de Direito Empresarial desde 1999. Atualmente,
também faz parte do Corpo Docente da Faculdade Damásio, ministrando a disciplina de Direito
Empresarial.

http://revistasapereaude.org/index.php/edicoes/ano-5-volume-4-novembro-2016

D.O.I: $10.20523 /$ sapereaude-ano5-vol-4-pg-40-65 


\section{INTRODUÇÃO}

O factoring pode ser visto como um dos instrumentos ideais para servir de suporte às pequenas e médias empresas, embora ainda careça de uma disciplina jurídica específica em nosso país.

Uma das causas do crescimento do factoring se deve justamente às necessidades de captação de recursos para o giro ou expansão da atividade empresarial. Essa operação é considerada pelo mercado tomador como alternativa para a obtenção de recursos de curto prazo, em contrapartida às operações assemelhadas e desenvolvidas pelo sistema financeiro que, via de regra, são realizadas mediante a oferta de garantias, tendo em vista que a instituição financeira não arca com os riscos de inadimplência dos devedores de títulos caucionados por força da operação específica de mútuo ou de desconto.

A utilização da técnica do factoring permite aos empreendedores perseguir variados objetivos, como a simplificação e racionalização da gestão empresarial, maior agilidade na cobrança dos créditos, transferência dos riscos de inadimplência dos devedores e maior disponibilidade de capital de giro para aplicar em seus negócios, o que nos conduz a identificar a função econômica do factoring.

No Brasil, ainda não há uma lei específica regulamentando a atividade de factoring, mas a falta de legislação não tem impedido a operacionalização do instituto e a sua validação jurídica, com bons resultados na atividade empresária.

\section{ORIGEM HISTÓRICA}

\subsection{Origem do factoring}

O factoring, como negócio, teve origem na Inglaterra, no século $\mathrm{XVI}$, sendo utilizado exclusivamente no mercado têxtil, no setor de lã. Os fabricantes de produtos

http://revistasapereaude.org/index.php/edicoes/ano-5-volume-4-novembro-2016 D.O.I: $10.20523 /$ sapereaude-ano5-vol-4-pg-40-65 
de lã incumbiam determinados comerciantes (factors) de vender seus produtos a terceiros em nome próprio, em troca do pagamento de uma comissão estipulada.

Após a descoberta e colonização da América, esses comerciantes ingleses passaram também a operar na colônia, onde, no exercício da função de factors que muito se assemelhava à comissão mercantil, não apenas administravam os estoques de produtos têxteis e outras mercadorias, para os seus proprietários na Europa, vendendo-os, inclusive, assim como garantiam o pagamento como agentes de crédito.

Com o desenvolvimento das colônias, o comércio reclamava a necessidade de institutos que amenizassem problemas, como a lentidão das vias de comunicação, a distância enorme entre o local de produção dos bens e 0 de sua efetiva comercialização. O factor, por sua vez, ao se transferir para as colônias, onde os produtos deveriam ser negociados, tinha condições de analisar melhor as características do mercado e de possuir a forma mais adequada de colocar os produtos junto à clientela.

Carlos Alberto Ghersi² compartilha da mesma opinião:

"Si bien alguns historiadores encuentran la génesis de esta figura contractual ya en las costumbres y usos comerciales de los fenicios, podemos decir que surge como tal y com las modalidades propias que han traído hasta la actualidad, a fins del siglo XVIII, cuando en pleno auge de la colonización europea en América, los empresarios ingleses (en especial, los industriales textiles), ante la necesidad de conquistar nuevos mercados, enviaban a las colonias de ultramar factors (agentes), para colocar sus productos en la plaza".

Com a independência das colônias inglesas, os factors tiveram que dinamizar sua atividade e aumentar suas funções, em virtude da criação de leis protecionistas que favoreciam a indústria têxtil local. Dessa forma, o factoring foi se expandindo principalmente nos Estados Unidos. Nessa oportunidade houve uma mudança da característica dessa operação, passando o factor a terceiro à responsabilidade pelo recebimento, guarda e venda das mercadorias, ficando apenas com o encargo do

http://revistasapereaude.org/index.php/edicoes/ano-5-volume-4-novembro-2016

D.O.I: $10.20523 /$ sapereaude-ano5-vol-4-pg-40-65 
recebimento das vendas e a antecipação do valor delas ao vendedor, mediante a dedução de uma comissão a título de remuneração.

Assim, o factoring foi introduzido como técnica destinada a constituir serviços e, em consequência, recursos para o giro dos negócios das indústrias têxteis americanas daquela época, além de ser um instrumento promocional e mercadológico capaz de transformar as vendas a prazo em vendas à vista.

Verifica-se que o factoring evoluiu afastando-se de sua natureza jurídica muito assemelhada a simples contrato de comissão para constituir um contrato em que o factor tem a função de fornecedor de recursos ao vendedor.

A promoção das vendas era realizada por força da aquisição, pelas factoring houses, dos créditos mercantis, abastecendo assim o caixa de suas clientes, que substituíram, a partir desse apoio, a análise técnica de riscos e de concessão de crédito mercantil, eximindo-se do encargo de avaliar a capacidade da empresa devedora da transação e as condições de mercado.

Essa mudança de orientação ocorreu lentamente, enquanto as operações de factoring se expandiam nos Estados Unidos e se extinguiam na Europa. Contudo, o factoring ressurgiu na Europa em 1960, assumindo o factor a função de financiador dos empresários.

Portanto, o factoring, como atualmente é conhecido, surgiu nos Estados Unidos, em meados do século XIX; inicialmente realizado no setor têxtil e, após a Segunda Guerra Mundial, diversificado para outros setores industriais, havendo cada vez mais a tendência à diversificação de ramos que operam com empresas de factoring.

\subsection{A evolução do factoring no Brasil}

${ }^{2}$ Contratos civiles y comerciales. $2^{\underline{a}}$ ed. Buenos Aires: Editorial Astrea de Alfredo y Ricardo Depalma, http://revistasapereaude.org/index.php/edicoes/ano-5-volume-4-novembro-2016 
No Brasil, com a edição da Circular nº 703, de 16 de junho de 1982 pelo Banco Central, as operações de factoring foram tipificadas como financeiras e, portanto, privativas de instituição financeira, criando verdadeira celeuma no meio jurídico. Esse diploma legal não proibia propriamente o factoring, mas considerava como financeiras as operações de aquisição, administração e garantia de liquidez dos direitos creditórios de pessoas jurídicas, decorrentes do faturamento da venda de seus bens e serviços, e que, portanto, somente as instituições financeiras estariam autorizadas a praticá-las, sob pena de outras pessoas responderem por crime.

Por conta desse entendimento, as Juntas Comerciais foram proibidas de proceder ao arquivamento de sociedades que tivessem como objeto social operações de factoring ${ }^{3}$. Além disso, enquanto a matéria não fosse regulamentada pelo Conselho Monetário Nacional, as pessoas físicas ou jurídicas não autorizadas que realizassem tais operações estariam sujeitas às penas previstas no $\S 7^{\circ}$ do artigo 44 da Lei $n^{\circ}$ $4.595 / 64$.

Apesar de toda polêmica surgida com a Circular 703, a referida norma acabou sendo revogada pela Circular no 1.359, de 30 de setembro de 1988, em decorrência do julgamento da Apelação no Mandado de Segurança no 99.964-RS, de 13 de maio de 1986, publicado no DJU de 12 de junho de 1986, pela Segunda Turma do Tribunal Federal de Recursos que autorizou o DNRC - Departamento Nacional do Registro do Comércio a liberar as Juntas Comerciais de todo o país a proceder o arquivamento dos atos constitutivos de sociedades de factoring, que até então estavam proibidas de proceder ao registro.

1992, p. 149.

${ }^{3} \mathrm{E}$ importante apresentar uma ocorrência histórica. Antes da tentativa de regulação do factoring, profissionais da área já haviam dado um grande passo para o crescimento do instituto no país. Em 11 de fevereiro de 1982, Luiz Lemos Leite, ex-diretor da Área de Mercado de Capitais do Banco Central, juntamente com 11 empresas, fundara a ANFAC - Associação Nacional das Empresas de Factoring, cujo objetivo era a associação das empresas de factoring e a divulgação da atividade perante as pequenas e médias empresas.

http://revistasapereaude.org/index.php/edicoes/ano-5-volume-4-novembro-2016

D.O.I: $10.20523 /$ sapereaude-ano5-vol-4-pg-40-65 
O Departamento Nacional de Registro do Comércio, seguindo a decisão do Tribunal Federal de Recursos, por intermédio da Instrução Normativa 16, em 19 de dezembro de 1986, passou a permitir o arquivamento dos atos constitutivos das empresas que se dedicassem ao factoring.

O Banco Central, por sua vez, achou por bem, rever sua posição a respeito do factoring, criando a Circular 1.395, publicada no Diário de Justiça da União em 3 de outubro de 1988, a qual revogou a Circular 703, ao reconhecer o caráter mercantil da operação.

Se no primeiro momento as operações de factoring foram inibidas no país, em virtude de medida adotada pelo próprio Banco Central, em momento posterior, essa atividade considerada mercantil proliferou, a ponto de seus defensores discutirem a necessidade de uma legislação específica sobre o assunto.

Até o momento, ainda não foi aprovada legislação que regulamente o instituto do factoring, embora houvesse sido apresentado à Câmara dos Deputados o Projeto de Lei 230/1995, de autoria do ex-senador José Fogaça, após surgiu o Projeto de Lei 3.615/2000 para disciplinar o factoring de exportação e, no mesmo ano, o Projeto de Lei 3.896/2000 ampliando a regulamentação e assimilando os dois anteriores e, posteriormente, o projeto de Lei 13/2007, que ficou prejudicado pela Lei Complementar no 123/2006, que institui o Estatuto Nacional da Microempresa e da Empresa de Pequeno Porte.

\section{ASPECTOS RELEVANTES}

\subsection{Conceito de factoring}

O modelo de factoring defendido, atualmente, não se limita apenas às operações de compra e venda de créditos ou à cessão simplesmente. 
Contudo, há um conceito tradicional de factoring, na doutrina, como cessão onerosa de crédito. Nessa linha, Orlando Gomes ${ }^{4}$ conceitua: "Factoring é o contrato por via do qual uma das partes cede a terceiro (o factor) créditos provenientes de vendas mercantis, assumindo o cessionário o risco de não recebê-los contra o pagamento de determinada comissão a que o cedente se obriga."

Há autores, como Fábio Konder Comparato ${ }^{5}$, que entende como venda do faturamento de uma empresa. Sustenta, no entanto, que na operação estão presentes os serviços de gestão de crédito e de garantia contra o risco de inadimplemento dos créditos transferidos, podendo comportar um financiamento na modalidade conventional factoring.

Para Waldírio Bulgarellí, o factoring também deve ser tratado como venda do faturamento de uma empresa à outra, que se incumbe de cobrá-lo, recebendo em pagamento uma comissão e cobrando juros quando antecipa recursos por conta dos recebimentos feitos.

Da análise de tais conceitos, pode-se depreender que nas operações de factoring há cessão de créditos provenientes de vendas mercantis ou a venda do faturamento de uma empresa. Porém, parece-nos que estes elementos não são suficientes para uma noção atual do instituto e de sua importância.

Não obstante a falta de legislação específica sobre o assunto, a Resolução № 2.144, de 22 de fevereiro de 1995, do Conselho Monetário Nacional, que ficou conhecida como o marco da admissão do factoring como atividade mercantil, o conceitua como: "a atividade de prestação cumulativa e contínua de serviços de assessoria creditícia, mercadológica, gestão de créditos, seleção de riscos, administração de contas a pagar e a receber, e compras de direitos creditórios resultantes de vendas mercantis a prazo ou de prestação de serviços."

\footnotetext{
${ }^{4}$ Contratos. $24^{\text {a }}$ ed., Rio de Janeiro: Forense, 2001, p. 468.

${ }^{5}$ Ensaios e pareceres de direito empresarial. Rio de Janeiro: Forense, 1978, p. 347.

${ }^{6}$ Contratos mercantis.14a ed. São Paulo: Atlas, 2001, p. 541.
}

http://revistasapereaude.org/index.php/edicoes/ano-5-volume-4-novembro-2016

D.O.I: $10.20523 /$ sapereaude-ano5-vol-4-pg-40-65 
O mesmo conceito lhe é atribuído na Lei oㅜ 9.249, de 26 de dezembro de 1995, artigo 15, § 1, III, d, embora para fins tributários. Ademais, a Emenda oㅜ 03- CAE (Substitutivo) apresentada ao Projeto de Lei da Câmara no 13, de 2007, que dispõe sobre o fomento empresarial, conceitua:

"contrato de fomento empresarial é aquele pelo qual uma parte transmite à outra, total ou parcialmente, a título oneroso, créditos decorrentes de suas atividades empresariais. Parágrafo único. O contrato de fomento empresarial poderá prever, ainda, a prestação de serviços relacionados à atividade empresarial, tais como: I - assessoria sobre o processo produtivo ou mercadológico; II - avaliação e seleção de clientes ou fornecedores; III - análise e gestão de créditos; IV acompanhamento de contas a pagar e a receber".

Por esses diplomas legais, constata-se que o factoring além da aquisição de créditos, envolve operações de gestão de crédito, serviços de seleção de riscos, administração de contas a receber e a pagar, cobrança, proteção contra riscos de crédito e fornecimento de recursos.

Assim, alguns pesquisadores e defensores têm atribuído um conceito mais amplo ao instituto. Para Luiz Lemos Leite" "o factoring é um contrato de natureza mercantil mista atípica, com prazo indeterminado, celebrado, via de regra, entre uma empresa produtora de bens ou serviços, e uma sociedade de factoring, abrangendo prestação de serviços e compra de direitos resultantes de vendas mercantis, em caráter contínuo". Diante desse conceito, o factoring é tratado como fomento mercantil.

Ives Gandra da Silva Martins ${ }^{8}$ afirma que "a operação de factoring não pode ser entendida com uma simples transferência de créditos ou direitos ou, o que é um absurdo, uma alternativa para burlar normas de direito bancário ou do direito comercial." Justifica seu entendimento, no fato de tratar-se de uma operação complexa, composta de vários serviços, de forma que somente um contrato que inclua a realização de, no mínimo, dois serviços elencados pela Convenção de Ottawa, de maio de 1988, organizada pelo Unidroit e patrocinada pelo Canadá.

\footnotetext{
${ }^{7}$ Factoring no Brasil, $7^{\mathrm{a}}$ ed. São Paulo: Atlas, 2001, p. 341.

${ }^{8}$ Factoring. Revista Jurídica. Porto Alegre: Editora Síntese Ltda., n. 240, p. 5-6, outubro de 1997, p. 5.
}

http://revistasapereaude.org/index.php/edicoes/ano-5-volume-4-novembro-2016

D.O.I: $10.20523 /$ sapereaude-ano5-vol-4-pg-40-65 
No direito comparado, também há autores que procuram dar uma dimensão mais abrangente ao instituto. Ricardo Luis Lorenzetti ${ }^{9}$ entende o factoring como:

"un contrato de colaboración, de larga duración, mediante el cual una de las partes, el factoreado, se obliga a efectuar una cesión global de créditos futuros que posee contra los clientes de su empresa, sometida a la condición suspensiva de la aprobación del factor, éste, por su parte, se obliga a aceptarlos conforme criterios objetivos, a dar un crédito por el asesoramento. Como puede advertirse es un contrato complejo, donde concurrem elementos de la cesión, del mutuo, de locación de servicios, y de la garantía".

Para Juan Rocca Guillamón ${ }^{10}$ :

"el factoring consiste en una actividad de cooperación empresarial que tiene por objeto, para el factor, la adquisición en firme a los productores de bienes o prestadores de servicios de los créditos de que sean titulares contra sus clientes o compradores, garantizando su satisfacción y prestando servicios complementarios de contabilidad, estudio de mercados, investigación de la clientela, etc., a cambio de una retribución, mediante anticipos com devengo de interesses."

Afirma ainda o autor ${ }^{11}$ "Decir que el factoring consiste en una cesión de créditos sin derecho de regreso-prestación principal-y otras prestaciones de servicios contables, estadísticos, etc., pero que no es una comisión mercantil, ni un seguro de créditos, ni una operación de descuento, es decir muy poco o casi nada."

O factoring pode abranger um sem número de operações, dadas às características próprias do instituto e a necessidade de fomento da atividade mercantil nas mais diversas áreas da empresa, podendo, perfeitamente serem acatadas as conceituações de Ricardo Lorenzetti e Guillamón.

\subsection{Modalidades de factoring}

${ }^{9}$ Tratado de los contratos. Tomo II. Buenos Aires: Rubinzal - Culzoni Editores, s.d,. págs. 120 a 121.

${ }^{10}$ El contrato de factoring y su regulación por el derecho privado español, Espanha: Editoriales de Derecho Reunidas, 1977, p. 2.

11"GUILLAMÓN, Juan Rocca. Ob. Cit., p. 25.

http://revistasapereaude.org/index.php/edicoes/ano-5-volume-4-novembro-2016

D.O.I: $10.20523 /$ sapereaude-ano5-vol-4-pg-40-65 
Inexiste na doutrina uma uniformidade terminológica quanto à classificação do factoring. Newton de Lucca ${ }^{12}$ afirma que as modalidades de factoring são tão distintas uma das outras que dificulta a formulação de um conceito unitário sobre o instituto.

No Brasil, as modalidades de factoring praticadas, segundo Antonio Carlos Donini ${ }^{13}$ são: convencional, importação-exportação, maturity, trustee e a compra de matéria-prima.

Dentre essas modalidades, as que mais interessam no estudo da matéria, são o conventional e o maturity factoring.

O convencional factoring caracteriza-se pelo pagamento à vista feito pela faturizadora, conjugado ou não com a prestação de uma série de serviços ao faturizado e a garantia do risco relativo ao não pagamento. Essa modalidade é considerada por alguns doutrinadores como de financiamento ${ }^{14}$.

No maturity factoring, o pagamento é feito pela faturizadora somente no vencimento, também conhecido como factoring sem financiamento. Nessa modalidade a faturizadora pode ou não prestar serviços ao faturizado, mas está presente a garantia do risco do crédito, embora o pagamento seja feito no vencimento ou em data prefixada, esse pagamento independe do recebimento efetivo do crédito pela faturizadora ${ }^{15}$.

Carlos Alberto Ghersi ${ }^{16}$ apresenta, no entanto, duas variantes para essa modalidade: "a) El factor se compromete a pagar las facturas por ventas solo em la

\footnotetext{
12 Faturização no direito brasileiro. São Paulo: Revista dos Tribunais, 1986, p. 19.

${ }^{13}$ Factoring de acordo com o novo código civil. Rio de Janeiro: Forense, 2002, págs. 11 a 12.

${ }^{14}$ Como Fábio Konder Comparato, Newton de Lucca, Orlando Gomes, Fran Martins e Juan Rocca Guillamón.

${ }^{15}$ LOPES, Maria Elizabete Vilaça. O contrato de "factoring" e o sistema financeiro nacional. Revista de Direito Mercantil, Industrial, Econômico e Financeiro. São Paulo: Revista dos Tribunais, no 74 , p. 5771, abril/junho de 1989, p. 59.

${ }^{16}$ Contratos civiles $\boldsymbol{y}$ comerciales, $2^{\underline{a}}$ ed. Buenos Aires: Editorial Astrea de Alfredo y Ricardo Depalma, 1992, p. 156.
}

http://revistasapereaude.org/index.php/edicoes/ano-5-volume-4-novembro-2016

D.O.I: 10.20523/sapereaude-ano5-vol-4-pg-40-65 
medida em que los deudores de la empresa factoreada cancelen sus deudas em los plazos convenidos. El factor no asume aquí el riesgo de cobrabilidad. b) El factor se compromete a pagar por los créditos adquiridos un importe fijado en el contrato, al vencimiento de ellos o en una fecha determinada, con independencia de que los deudores del cliente cancelen o no sus deudas. La entidad de factoring acepta la transferencia de los créditos con sus riesgos."

Para que o maturity seja considerado modalidade de factoring mais interesse aos clientes, o ideal é que possua a segunda variante, pois o faturizado não precisará se preocupar com riscos de inadimplência.

O trustee, por sua vez, se apresenta como prestação de serviços ao faturizado, como administração de contas a receber e a pagar, em que a faturizadora age como mandatária da empresa-cliente. No trustee não há uma cessão de crédito, mas uma prestação de serviços variados.

$\mathrm{Na}$ modalidade compra de matéria-prima, a faturizadora adquire junto ao fornecedor matéria-prima, insumo e estoque para a produção do faturizado, em contrapartida, o fornecedor terá direitos de exclusividade sobre a venda dos produtos resultantes dessa matéria-prima. A responsabilidade da faturizadora pelo pagamento poderá ser direta ou indireta, se adquirir o produto em nome próprio ou, em nome do faturizado, mas como única responsável17.

Fran Martins ${ }^{18}$ classifica a faturização em interna e exterior. As operações podem ser realizadas dentro do mesmo país, ou, neste, dentro de uma região: a esse tipo de faturização, chama-se faturização interna. A faturização também pode se relacionar com operações a serem realizadas fora do país, como em operações de importação e exportação, considerando esse tipo como faturização exterior.

\footnotetext{
${ }^{17} \mathrm{DONINI}$, Antonio Carlos. Factoring de acordo com o novo código civil. Rio de Janeiro: Forense, 2002, p. 40.

${ }^{18}$ Contratos e obrigações comerciais. $15^{\mathrm{a}}$ ed. Rio de Janeiro: Forense, 2000, p. 477.
}

http://revistasapereaude.org/index.php/edicoes/ano-5-volume-4-novembro-2016

D.O.I: $10.20523 /$ sapereaude-ano5-vol-4-pg-40-65 
Irineu Strenger ${ }^{19}$ distingue o domestic factoring do factoring internacional, que é utilizado por empresas que possuem relações comerciais com o exterior. A empresa que realiza operações internacionais deve se socorrer de um factor nacional (export factor) o qual solicita a seu correspondente no estrangeiro (import factor) a aprovação do crédito. O import factor, por sua vez, procura obter informações acerca do adquirente e, de posse das informações, comunica ao export factor, o qual leva ao conhecimento do seu cliente. O contrato de venda, entre o exportador e o cliente estrangeiro, somente se aperfeiçoa com a aprovação do crédito, obtida mediante às informações do import factor e repassadas ao export factor. Assim, concluída a operação, o cliente estrangeiro deverá efetuar o pagamento do preço do bem adquirido ao import factor, que se transforma em cessionário do crédito que a empresa nacional constitui em relação ao cliente estrangeiro.

A par de tais explanações, pode-se constatar que o factoring internacional pressupõe a existência de dois contratos de factoring, o primeiro entre uma empresa exportadora e o factor exportador, cujo objeto é a cessão dos créditos de que a empresa passa a ser titular e, o segundo, é celebrado entre o factor importador e o factor exportador, que resulta ao import factor a obrigação de obter informações acerca da solvência dos adquirentes, receber o pagamento do crédito e enviar o valor recebido ao export factor que, por seu turno, o repassará ao cliente exportador descontando-se o valor da comissão.

Percebe-se, por isso, que o factor tem uma importância preponderante no factoring internacional, na medida em que a operação de exportação só se concretiza, com a aprovação do crédito, mediante as informações prestadas pelo import factor ao export factor.

\subsection{Função econômica do factoring}

${ }^{19}$ Contratos internacionais do comércio. $2^{2}$ ed. São Paulo: Revista dos Tribunais, 1992, p. 327.

http://revistasapereaude.org/index.php/edicoes/ano-5-volume-4-novembro-2016 
O crescimento do factoring deve-se, principalmente às dificuldades existentes no acesso ao crédito em nosso país, em virtude do aumento do custo do dinheiro e em decorrência das exigências impostas pelo sistema bancário às pequenas e médias empresas.

Diante disso, constata-se as dificuldades dessas empresas em obter capital de giro necessário para o incremento de sua produção ou comercialização, sendo obrigadas a recorrer a mecanismos alternativos, como o factoring.

A função econômica do factoring em nosso país, parece não destoar de outras legislações, consoante nos assevera Juan M. Farina ${ }^{20}$ :

\begin{abstract}
"En virtud de este contrato la empresa puede aumentar la velocidad de rotación de su capital circulante, lo cual le ha de permitir un mayor volumen de ventas, sobre todo cuando el riesgo que significan los morosos e insolventes es asumido por la empresa de factoring que, además, según las modalidades, puede conceder anticipos de hasta el ciento por ciento da la facturación. La solvencia de los clientes del factoreado es calculada por la empresa de factoring en forma global, y no com respecto a cada adquirente en particular. La consecuencia, por tanto, es que la empresa factoreada puede aumentar su capacidad de concesión de crédito; y también facilita la exportación a empresas que no tienen una adecuda estructura".
\end{abstract}

Como consequência da função econômica do factoring, advém certas vantagens à empresa faturizada, dentre as quais pode-se destacar: facilidade das empresas na obtenção do capital de giro, sem a necessidade de uma análise rigorosa na situação econômico-financeira; transformação das vendas a prazos em a vista, já que o pagamento é realizado pelo factor no momento da cessão, independente do vencimento do crédito; responsabilidade do factor pelo risco de inadimplência e insolvência do devedor, o que possibilita à faturizada ter total disponibilidade sobre o valor obtido com a cessão do crédito, sem ter que responder em regresso; terceirização de serviços de assessoria creditícia, mercadológica e financeira, permite à faturizada

\footnotetext{
${ }^{20}$ Contratos comerciales modernos. $1^{\text {a }}$ reimpressão. Buenos Aires: Editorial Astrea de Alfredo y Ricardo Depalma, 1994, p. 528.
}

http://revistasapereaude.org/index.php/edicoes/ano-5-volume-4-novembro-2016

D.O.I: 10.20523/sapereaude-ano5-vol-4-pg-40-65 
deslocar suas atenções para a atividade produtiva da empresa, sem se preocupar com questões operacionais ou burocráticas.

Assim como são oferecidas vantagens, também resultam desvantagens à empresa faturizada no que tange aos custos da operação, acarretando a redução da margem de lucros. No valor da comissão cobrada pelo factor são computados além de juros, correção monetária e despesas de operacionalização, o valor do risco do negócio. Isto é, se os créditos são adquiridos pro soluto, no preço da remuneração já estão embutidos eventuais riscos de inadimplência, atrasos no pagamento e insolvência do devedor.

Jacobo Leonis ${ }^{21}$ assinala a desvantagem econômica e financeira "diz-se que o custo do factoring é caro, tanto em suas comissões como em juros, quando também se pactua o serviço financeiro, não obstante possamos considerar que, com ele, se reduzem gastos fixos ou estruturais das empresas "clientes" - que incidem sobre elas tanto em épocas de pleno rendimento como de recessão - e que os bancos somente concedem créditos em função da solvência que lhes merece o prestatário."

Desta forma, podemos afirmar que as técnicas utilizadas nas operações de factoring, ou seja, pagamento dos créditos a vista, inexistência de direito de regresso contra o faturizado e o valor cobrado pelos serviços de gestão, fazem com que o custo das operações possam intervir diretamente na atividade econômica do empresário, acarretando redução em sua margem de lucros ou elevação no preço de seus produtos ou serviços no mercado.

As normas contratuais resultantes das operações de factoring interferem nos custos da atividade empresarial, não apenas para empresa cliente, como também para a própria sociedade de factoring, resultando no que Fábio Ulhoa Coelho ${ }^{22}$ considera direito-custo ou o custo do direito para a atividade empresarial, que define como

\footnotetext{
${ }^{21} O$ contrato de "factoring". Trad. Ignácio de Aragão (advogado no Rio de Janeiro). Revista Forense. Rio de Janeiro: n. 253, p. 458-468, janeiro/fevereiro/março de 1976. Revista Forense, v. 253, p. 463.

${ }^{22}$ Curso de direito comercial. $6^{\mathrm{a}}$ ed. São Paulo: Saraiva, 2002, v. 1, p. 40.
}

http://revistasapereaude.org/index.php/edicoes/ano-5-volume-4-novembro-2016 
"normas jurídicas cuja aplicação interfere com os custos da atividade empresarial, da produção ou circulação de bens ou serviços."

Num sistema capitalista como o nosso, o empresário está acostumado a repassar os custos de sua atividade econômica para os consumidores, assim, as empresas que costumam se utilizar de operações de factoring podem pretender agregar aos preços de seus produtos ou serviços, os custos que essas operações Ihes proporcionem. Logo, quanto maior o custo maior será o preço para a atividade empresarial.

\section{NATUREZA JURÍDICA DA OPERAÇÃO}

Há na doutrina divergências no que tange a natureza jurídica do factoring. Alguns doutrinadores procuram identificá-lo como simples compra de créditos, de faturamento; e outros como mera cessão de créditos.

O factoring é mais do que a simples compra ou cessão de créditos e, ainda que concorram fundamentos de outros institutos, sua natureza jurídica não se amolda a qualquer contrato típico, ficando a depender de uma legislação específica ${ }^{23}$.

A complexidade da operação de factoring também pode ser analisada sob o prisma das relações existentes entre as partes. O factoring, por si só, tem uma estrutura relativamente simples, pois formaliza-se através de uma contrato celebrado entre as partes, porém, as relações que dele derivam entre cedente e factor é que são complexas.

No entendimento do autor espanhol Juan Rocca Guilamón²4 "Decir que el factoring consiste en una cesión de créditos sin derecho de regreso-prestación principal-y otras prestaciones de servicios contables, estadísticos, etc., pero que no es

\footnotetext{
${ }^{23}$ VENOSA, Sílvio de Salvo. Direito Civil: Contratos em espécie e responsabilidade civil. São Paulo: Atlas, 2001, v. 3, p. 476.

${ }^{24} J u a n$ Roca Guillamón. El contrato de factoring y su regulación por el derecho privado español. Espanha: Editoriales de Derecho Reunidas, 1977, p. 35.
}

http://revistasapereaude.org/index.php/edicoes/ano-5-volume-4-novembro-2016

D.O.I: $10.20523 /$ sapereaude-ano5-vol-4-pg-40-65 
una comisión mercantil, ni un seguro de créditos, ni una operación de descuento, es dir muy poco o casi nada."

Para esse doutrinador o fato de envolver figuras jurídicas já conhecidas, não justifica a autonomia do contrato de factoring. Mas sustenta "Hemos admitido que el factoring se nos ofrece como un negócio contractual atípico, que origina una situación jurídica compleja, en cuyo ámbito se dan distintos mecanismos jurídicos típicos que, sin perder su autonomía conceptual, se desenvuelven dentro de los límites impustos por el fin económico-social y el interés que constituyen el objeto del contrato."

O que justifica a autonomia do factoring, sem dúvida é a criação de uma relação jurídica entre as partes, não prevista propriamente em leis, mas constituída a partir de outras figuras jurídicas e, que visa atender a uma finalidade econômico-social, considerada em seu conjunto.

É indubitável a natureza complexa das atividades de factoring, que na sua operacionalização utiliza-se de institutos já conhecidos no direito, porém, sem perder a sua autonomia.

Além disso, o factoring, como negócio jurídico complexo, está disciplinado em um contrato em que se estabelecem as relações entre as partes, do qual deriva um vínculo obrigacional de conteúdo patrimonial entre os contratantes.

Portanto, o factoring está amparado em uma relação jurídica de caráter contratual, cujo contrato pode ser classificado como bilateral, consensual, oneroso, aleatório, de execução continuada, interempresarial e atípico.

Sua classificação, no entanto, não se amolda a qualquer contrato típico, na medida em que não há uma lei específica regulando os direitos e deveres entre as partes contratantes. De modo que, o conteúdo do contrato é formado a partir de normas de caráter civil e de caráter mercantil, que disciplinam os contratos em geral. Além de vigorar também o princípio da autonomia em matéria contratual.

http://revistasapereaude.org/index.php/edicoes/ano-5-volume-4-novembro-2016 
O factoring possui uma natureza jurídica contratual complexa, envolvendo várias figuras jurídicas, porém, ser perder a sua autonomia, como instituto jurídico próprio, mas atípico, porém, a merecer uma disciplina jurídica específica.

\section{ANÁLISE JURÍDICA DA OPERAÇÃO}

\subsection{Cessão de crédito ou endosso sem garantia}

A cessão de crédito é o principal mecanismo de transferência do crédito no factoring, tendo em vista a natureza contratual do instituto. Todavia, se o crédito é representado por títulos de crédito, como a duplicata, a sua transferência poderá ser feita por meio de endosso, por ser esse o instrumento de transferência do direito cambiário.

É da essência do factoring que a aquisição dos créditos seja feita "pro soluto", isto é, sem direito de regresso contra o faturizado. Aliás, essa é a principal característica que diferencia do desconto bancário.

Para a transferência dos créditos nas operações de factoring pode ser aplicado perfeitamente o endosso sem garantia, nos termos do artigo 15 do Decreto no $57.663 / 66$, inclusive, se o crédito estiver representado por duplicata.

No endosso sem garantia, o endossante não responde pela solvência do devedor, não sendo considerado um coobrigado pelo pagamento do título. Aliás, a própria Anfac admite o endosso sem garantia nos contratos de factoring 25 . Criticava-se que a cessão civil de crédito não podia atender a todas as complexas e abrangentes funções do factoring, principalmente, porque no contrato de cessão de crédito, a título oneroso, os direitos da empresa de factoring cessionária, podiam ser questionados,

\footnotetext{
${ }^{25}$ Convém ressaltar, que a cessão de crédito serviu de instrumento para operacionalizar o factoring no Brasil até 1982. Em agosto de 1989, a Anfac elaborou modelo denominado de "Contrato de Fomento Mercantil", admitindo que a transferência dos créditos fosse realizada mediante endosso sem garantia, alegando inadequação da disciplina do caráter geral da cessão. Desde então, as empresas filiadas a Anfac ao adotarem o modelo de contrato proposto, utilizam-se para a transferência dos créditos do endosso em preto, com cláusula sem garantia.
}

http://revistasapereaude.org/index.php/edicoes/ano-5-volume-4-novembro-2016 
tendo em vista que os títulos de crédito cedidos não constituíam uma obrigação autônoma, sendo necessário à análise da causa originária. Além disso, na cessão, a nulidade de um ato determina a nulidade dos atos posteriores.

Para amenizar o problema, a Anfac entendeu que o melhor caminho era o endosso em preto, com cláusula sem garantia, por ser a forma de transferência típica e exclusiva dos documentos cambiais, produzindo efeitos autônomos e independentes da relação principal.

A Anfac ao preconizar a inclusão do endosso sem garantia, nas operações de factoring, também o fez com base no princípio da liberdade contratual, porém, assevera, o que já foi anteriormente concluído, que o factoring não se exaure em uma cessão de crédito, ao revés disso, possui uma natureza complexa26.

Pode-se perfeitamente aplicar às operações de factoring, o endosso, com cláusula sem garantia, em virtude da própria natureza contratual do instituto ora tratado e não cambial, que admite a utilização de certas figuras jurídicas, mediante certas adaptações, até mesmo do endosso sem garantia.

\subsection{Notificação do devedor}

No factoring, a transferência dos créditos pode ocorrer com ou sem notificação dos devedores, mas se os créditos são cedidos à notificação é essencial para tornar eficaz a cessão ao devedor ${ }^{27}$. Mas se os créditos estiverem representados por títulos cambiais, ou cambiariformes, por exemplo, duplicatas, e forem transferidos por meio de endosso, a faturizadora terá legitimação para exigi-los. ${ }^{28}$

\footnotetext{
${ }^{26}$ LEITE, Luiz Lemos. Factoring no Brasil. 7ª ed. São Paulo: Atlas, 2001, p. 259.

${ }^{27}$ Conforme artigo 290 do Código Civil: "A cessão do crédito não tem eficácia em relação ao devedor, senão quando a este notificada; mas por notificado se tem o devedor que, em escrito público ou particular, se declarou ciente da cessão feita".

${ }^{28}$ COMPARATO, Fábio Konder. Factoring. Revista de Direito Mercantil, Industrial, Econômico e Financeiro. São Paulo: Revista dos Tribunais, n. 6, p. 59-66, 197, p. 61.
}

http://revistasapereaude.org/index.php/edicoes/ano-5-volume-4-novembro-2016

D.O.I: $10.20523 /$ sapereaude-ano5-vol-4-pg-40-65 
A doutrina estrangeira parece compartilhar do entendimento, segundo o qual na fatura enviada ao devedor deve constar que o pagamento seja feito ao factor. Conforme Juan M. Farina "Es necesario que sobre las facturas adquiridas por el factor y enviadas a los clientes se aclare expresamente que en adelante el pago de esa factura sólo tendrá efecto liberatório si es afectuado a la sociedad de factoring"29. Sobre o assunto, reafirmam Sebastião Nóbrega Pizarro e Margarida Mendes Calixto "A prática corrente parece ser, no entanto, a inclusão nos documentos, facturas que titulam os créditos, da menção de que o pagamento só se torna liberatório quando efectuado ao factor."30

É comum, no contrato de factoring, as partes já estabelecerem cláusula prevendo a necessidade de notificação do devedor. Tal praxe se verifica no modelo de contrato de fomento mercantil proposto pela Anfac, em que a transferência dos créditos é realizada por endosso em preto, com cláusula sem garantia.

A cessão dos créditos ao factor, independe da anuência do devedor sacado. Para a validade da cessão ou transferência de créditos comerciais não se exige a aprovação ou o consentimento do devedor, mas tão-somente sua notificação, ainda que não esclareça quem ou como se deva fazê-la. ${ }^{31}$

A notificação da cessão de crédito pode gerar certo receio aos empreendedores, porque pode sugerir aos clientes uma situação de iliquidez ou insolvência econômica. É o caso do Direito norte-americano, onde desenvolveu-se a técnica da "non notification factoring", em virtude do preconceito de que a empresa que cede os seus créditos a terceiros estaria numa má situação. Assim, compete ao cedente faturar os créditos e cobrá-los do sacado, transferindo o valor correspondente ao faturizador. No caso do Brasil, isto não acontece, tendo em vista que os empresários aqui já estão

\footnotetext{
${ }^{29}$ Contratos comerciales modernos. $1^{\underline{a}}$ reimpressão. Buenos Aires: Editorial Astrea de Alfredo y Ricardo Depalma, 1994, p. 530.

${ }^{30}$ Contratos financeiros. $2^{\mathrm{a}}$ ed. Coimbra: Livraria Almedina, 1995, p. 146.

${ }^{31}$ LEONIS, Jacobo. O contrato de factoring. Trad. Ignácio de Aragão. Revista Forense. Rio de Janeiro: n. 253, p. 458-468, janeiro/fevereiro/março de 1976, p. 466.
}

http://revistasapereaude.org/index.php/edicoes/ano-5-volume-4-novembro-2016

D.O.I: $10.20523 /$ sapereaude-ano5-vol-4-pg-40-65 
familiarizados com o desconto bancário de títulos, ao contrário, do sistema jurídico norte-americano que não se utiliza dessa figura jurídica. ${ }^{32}$

No contrato de factoring tradicional, o devedor sacado não faz parte da relação jurídica, existente apenas entre o faturizado e o factor. Assim, a notificação tem por finalidade dar ciência ao devedor de que o crédito foi cedido, devendo pagar o valor respectivo ao cessionário faturizador.

Entretanto, se não for feita a notificação ou não se provando que o devedor teve ciência da notificação, a conseqüência será a validade do pagamento feito ao cedente.

A doutrina brasileira considera notificado o devedor, por escrito público ou particular, desde que tenha se declarado ciente da cessão. Basta, portanto, para a eficácia da cessão, a ciência expressa do sacado, independente da notificação ter sido realizada pelo cartório de títulos e documentos, por via judicial, por carta, telegrama ou por qualquer outro meio.

A notificação ainda tem a finalidade de possibilitar ao devedor impugnação alegando vícios, como pagamento anterior, prescrição, nulidade do título ou falta de causa ou origem do título. Trata-se da aplicação da oponibilidade das exceções pessoais admitida na cessão civil. Maria Helena Diniz ${ }^{33}$ explica:

"não se cortam todas as relações entre o credor originário e o devedor cedido, pois pelo Código Civil, art. $1.072^{34}$, este poderá opor tanto ao cessionário quanto ao cedente as exceções que lhe competirem no momento em que tiver ciência da cessão (...). Será conveniente que o devedor, ao ser notificado, ressalve o seu direito de oponibilidade. Assim sendo, se a obrigação for passível de anulação por erro, dolo ou incapacidade relativa do agente, ou se houve pagamento do débito ou mesmo compensação, o devedor só poderá argüir tal exceção ou esses vícios contra o cedente ou contra o cessionário, se reclamou

\footnotetext{
${ }^{32}$ COMPARATO, Fábio Konder. Factoring. Revista de Direito Mercantil, Industrial, Econômico e Financeiro. São Paulo: Revista dos Tribunais, n. 6, p. 59-66, 1972, p. 61.

${ }^{33}$ DINIZ, Maria Helena. Curso de direito civil brasileiro: Teoria geral das obrigações. 9a ed. São Paulo: Saraiva, 1995, v. 2, p. 350.

${ }^{34} \mathrm{O}$ artigo 1.072 do Código Civil Brasileiro corresponde, atualmente ao artigo 294 do Código Civil de 2002, com a seguinte redação: "O devedor pode opor ao cessionário as exceções que lhe competirem, bem como as que, no momento em que veio a Ter conhecimento da cessão, tinha contra o cedente."
}

http://revistasapereaude.org/index.php/edicoes/ano-5-volume-4-novembro-2016

D.O.I: $10.20523 /$ sapereaude-ano5-vol-4-pg-40-65 
ao ser notificado, porque seu silêncio equivalerá à anuência com os termos do negócio, indicando seu propósito de pagar ao cessionário a prestação devida. Mas, se não foi notificado da cessão, poderá opor ao cessionário aquelas exceções que contra o cedente tinha antes da transferência"..

Na cessão de crédito, uma vez alegada exceção pessoal pelo devedor, esbarrase na possibilidade do faturizado vir a ser responsabilizado em regresso pelo factor. A princípio, poder-se-ia sustentar, que se a cessão foi realizada "pro soluto", o factor não teria direito de regresso contra o faturizado. Até porque, no valor da comissão, já teriam sido devidamente computados os riscos do negócio, além do que, o factor possui condições de diluir eventuais prejuízos, na medida em que houver a cessão global dos créditos e a possibilidade de seleção dos mesmos. Entretanto, a situação é diversa, quando a cessão for "pro solvendo", pois o faturizador mantém garantido o direito de regresso contra o faturizado.

\subsection{Hipóteses de regresso contra o faturizado}

Como já foi enfatizado, o crédito poderá ser transferido ao factor por cessão civil ou por endosso, sendo mais comum o endosso de duplicatas.

No caso da cessão civil, o cedente é responsável pela existência do crédito e pela solvência do devedor, nesse caso, desde que expressamente convencionado pelas partes no contrato de factoring. Na primeira hipótese, como o cedente é responsável, se o crédito já estiver extinto, pela prescrição, ou pela suspensão de sua exigibilidade, ou depender de condição, o factor tem direito de acionar em regresso o faturizado. Essas hipóteses, contudo, devem ocorrer no momento da cessão, para que haja o direito de regresso. Trata-se de responsabilidade obrigatória do cedente por vício ${ }^{35}$.

${ }^{35} \mathrm{DONINI}$, Antonio Carlos. Factoring de acordo com o novo código civil. Rio de Janeiro: Forense, 2002, p. 103.

http://revistasapereaude.org/index.php/edicoes/ano-5-volume-4-novembro-2016

D.O.I: $10.20523 /$ sapereaude-ano5-vol-4-pg-40-65 
Ademais, a lei permite ao devedor, quando demandado pelo factor, alegar exceções pessoais mantidas com o faturizado, neste caso, o factor poderá acionar em regresso o faturizado, se o crédito não for certo, lícito ou regular ${ }^{36}$.

No que tange à solvência do devedor, desde que ajustado entre as partes, o cedente poderá se responsabilizar. É o caso, portanto, de responsabilidade opcional do cedente pela solvência do devedor, independente de vício ${ }^{37}$. A doutrina pátria costuma chamar esse tipo de cessão de pro solvendo.

O cedente possui responsabilidade obrigatória quanto aos vícios, por ocasião da cessão, tendo em vista que é responsável pela existência e legitimidade do crédito. No entanto, possui responsabilidade facultativa ou opcional quanto à solvência do devedor, tendo em vista a previsão legal, que admite a estipulação de cláusula prevendo a responsabilidade do cedente. Nesse caso, ter-se-á uma cessão pro solvendo.

No caso da transferência dos créditos ser realizada mediante endosso, os seus efeitos serão diversos da cessão no que se refere à responsabilidade. Por esse ato cambial, o endossante é responsável pela existência do crédito, bem como pela aceitação e pagamento do título.

O endosso pode ser utilizado para a transferência do crédito representado por duplicata na operação de factoring, mas se o devedor se recusar a pagar, o factor poderá voltar-se contra o faturizado, com base nas causas do artigo $8^{\circ}$ da Lei no 5.474/68 (Lei da Duplicata): "O comprador só poderá deixar de aceitar a duplicata por motivo de: I - avaria ou não recebimento das mercadorias, quando não expedidas ou não entregues por sua conta e risco; II - vícios, defeitos e diferenças na qualidade ou na quantidade das mercadorias, devidamente comprovados; III - divergência nos prazos ou nos preços ajustados."

\footnotetext{
${ }^{36}$ BULGARELLI, Waldírio. Contratos mercantis. 14a ed. São Paulo: Atlas, 2001, p. 545.

${ }^{37} \mathrm{DONINI}$, Antonio Carlos. Factoring de acordo com o novo código civil. Rio de Janeiro: Forense, 2002, p. 88.
}

http://revistasapereaude.org/index.php/edicoes/ano-5-volume-4-novembro-2016

D.O.I: $10.20523 /$ sapereaude-ano5-vol-4-pg-40-65 
Infere-se, assim, que nas operações de factoring, cujos créditos representados por duplicatas forem transferidos por endosso, o endossante pode ser responsabilizado por vícios ou defeitos existentes na coisa, principalmente por ser a duplicata título causal, possibilitando ao devedor a discussão da causa debendi.

\section{A esse respeito explica Arnaldo Rizzardo38:}

"Embora o endosso, no factoring, importe em transferência de propriedade do título, não se resumindo a um endosso mandato, não se desvincula o endossante da garantia, respondendo pela realidade do crédito. Asseguram-se ao devedor as exceções ou defesas próprias mesmo na transferência do título. Não prepondera o formalismo ou a abstratividade do endosso, desvinculando a exigibilidade da obrigação da causa debendi. Com efeito, dada a emissão antes da remessa da mercadoria, ou mesmo concomitantemente ao seu recebimento, e sendo a emissão ato unilateral do vendedor, ficaria sujeito a injustiças o devedor, caso sempre obrigado a pagar“.

Eduardo de Sousa Carmo ${ }^{39}$, por sua vez, afirma que as sociedades de factoring:

"não podem fazer uso do endosso-garantia cambial, porque, através dele, não desvinculariam o cliente da obrigação cartular; mas não podem, também, servirem-se da cessão de crédito, instituto que as tornaria inviáveis, por autorizar esta forma de transferência o exame da causa debendi de todos os títulos de crédito que adquirissem. Ninguém se interessaria por operar com faturização se a sociedade se visse, no futuro (vencido um determinado título de crédito), na contingência de ouvir do devedor, por exemplo, que a bicicleta por ele comprada (causa debendi do título de crédito) foi entregue a seu filho pelo vendedor (cliente da factoring e cedente do crédito) com as rodas empenadas".

Por fim, conclui o autor que o ato a ser utilizado pelo cliente do factor para a transferência dos créditos é o endosso sem garantia.

Há de se ressaltar, o caráter contratual e não cambial das operações de factoring, que permite as partes uma certa autonomia na fixação de cláusulas e condições visando otimizar a disciplina do instituto.

\footnotetext{
${ }^{38}$ Factoring. $2^{\mathrm{a}}$ ed. São Paulo: Revista dos Tribunais, 2000, p. 88.

${ }^{39}$ Endosso sem garantia e "factoring". Revista de Direito Mercantil. São Paulo: Revista dos Tribunais, n. 71, p. 55-61, julho/setembro de 1988, p. 57.
}

http://revistasapereaude.org/index.php/edicoes/ano-5-volume-4-novembro-2016

D.O.I: $10.20523 /$ sapereaude-ano5-vol-4-pg-40-65 
Assim, o endossante além de responsável pela existência do crédito, também responde pela solvência do devedor. Em tais situações, o factor se reserva o direito acionar o endossante-faturizado em regresso, seja pela existência, legitimidade do crédito, nas hipóteses do artigo $8^{\circ}$ da Lei ํo 5.474/68 ou, pela inadimplência do devedor, salvo, se houver, convenção em contrário determinada pelas partes no contrato.

Deverás, no que tange a responsabilidade pela inadimplência do devedor, o faturizado sempre poderá isentar-se dessa responsabilidade, utilizando-se do endosso sem garantia, quando os créditos estiverem representados por títulos ou, por intermédio de uma "cessão pro soluto", por constituir elemento essencial do factoring a assunção dos riscos pelo factor, servindo, inclusive, para diferenciá-lo do desconto bancário.

\section{CONCLUSÃO}

O factoring possui uma função social e econômica, principalmente por propiciar a cooperação entre as empresas, possibilitando a mobilização de capital e de trabalho necessários ao desenvolvimento da atividade empresarial, a despeito da inexistência de legislação específica sobre o tema.

Na sua operacionalização, verificou-se que o factoring pode envolver uma série de figuras jurídicas, de natureza diversa, porém, instrumentaliza-se por intermédio de um contrato, no qual devem ser observadas as normas gerais contratuais, especialmente os princípios do Código Civil que norteiam as relações jurídicas privadas em face da atividade econômica.

Partindo-se dessa visão generalizada, chegou-se à conclusão que várias são as técnicas utilizadas nas operações de factoring, passíveis de influenciar diretamente na atividade econômica do empresário, visto que as suas operações se desenvolvem a

http://revistasapereaude.org/index.php/edicoes/ano-5-volume-4-novembro-2016

D.O.I: 10.20523/sapereaude-ano5-vol-4-pg-40-65 
partir da necessidade de perenização da atividade empresarial, podendo influenciar diretamente no custo da atividade.

Espera-se que o direito projetado não vise apenas legalizar o factoring, mas no âmbito sócio-econômico preserve o factoring como mecanismo de fomento da produção e da atividade empresarial como um todo, protegendo e propiciando entendimento entre os agentes econômicos e toda a sociedade.

\section{BIBLIOGRAFIA}

\section{Livros}

BULGARELLI, Waldirio. Contratos mercantis. 14를. ed. São Paulo: Atlas, 2001.

COELHO, Fábio Ulhoa. Curso de Direito Comercial. $6^{\underline{a}}$ ed. São Paulo: Saraiva, 2002, v. 1.

COMPARATO, Fábio Konder. Ensaios e pareceres de direito empresarial. Rio de Janeiro: Forense, 1978.

DINIZ, Maria Helena. Curso de direito civil brasileiro. Teoria geral das obrigações. $9^{a}$ ed. São Paulo: Saraiva, 1995, v. 2.

DONINI, Antonio Carlos. Factoring de acordo com o novo código civil. Rio de Janeiro: Forense, 2002.

FARINA, Juan M. Contratos comerciales modernos. $1^{\underline{a}}$ reimpressão. Buenos Aires: Editorial Astrea de Alfredo y Ricardo Depalma, 1994.

GOMES, Orlando. Contratos. 24르 ed., Rio de Janeiro: Forense, 2001.

GHERSI, Carlos Alberto. Contratos civiles y comerciales. $2^{\mathrm{a}}$ ed. Buenos Aires: Editorial Astrea de Alfredo y Ricardo Depalma, 1992.

GUILLAMÓN, Juan Roca. El contrato de factoring y su regulación por el derecho privado español. Espanha: Editoriales de Derecho Reunidas, 1977.

LEITE, Luiz Lemos. Factoring no Brasil.7ª ed. São Paulo: Atlas, 2001.

http://revistasapereaude.org/index.php/edicoes/ano-5-volume-4-novembro-2016

D.O.I: $10.20523 /$ sapereaude-ano5-vol-4-pg-40-65 
LORENZETTI, Ricardo Luis. Tratados de los contratos. Tomo II. Buenos Aires: Rubinzal

- Culzoni Editores, s.d.

LUCCA, Newton de. A faturização no direito brasileiro. São Paulo: Revista dos Tribunais, 1986.

MARTINS, Fran. Contratos e obrigações comerciais. 15a ed. Rio de Janeiro: Forense, 2000.

PIZARRO, Sebastião Nóbrega e Margarida Mendes Calixto. Contratos Financeiros. $2^{\mathrm{a}}$ ed. Coimbra: Livraria Almedina, 1995.

RIZZARDO, Arnaldo. Factoring. 2ª ed. São Paulo: Revista dos Tribunais, 2000.

STRENGER, Irineu. Contratos internacionais do comércio. $2^{2}$ ed. São Paulo: Revista dos Tribunais, 1992.

VENOSA, Sílvio de Salvo. Direito civil: Contratos em espécie e responsabilidade civil. São Paulo: Atlas, 2001, v. 3.

\section{Artigos}

CARMO, Eduardo de Sousa. Endosso sem garantia e "factoring". Revista de Direito Mercantil. São Paulo: Revista dos Tribunais, n. 71, p. 55-61, julho/setembro de 1988.

COMPARATO, Fábio Konder. Factoring. Revista de Direito Mercantil, Industrial, Econômico e Financeiro. São Paulo: Revista dos Tribunais, n. 6, p. 59-66, 1972.

LEONIS, Jacobo. O contrato de "factoring". Trad. Ignácio de Aragão (advogado no Rio de Janeiro). Revista Forense. Rio de Janeiro: n. 253, p. 458-468, janeiro/fevereiro/março de 1976.

LOPES, Maria Elizabete Vilaça. O contrato de "factoring" e o sistema financeiro nacional. Revista de Direito Mercantil, Industrial, Econômico e Financeiro. São Paulo: Revista dos Tribunais, no 74, p. 57-71, abril/junho de 1989.

MARTINS, Fran. O contrato de "factoring" e sua introdução no direito brasileiro. Revista Forense: Rio de Janeiro: n. 262, p. 9-14, abril/maio/junho de 1978.

SILVA MARTINS, Ives Gandra da. Factoring. Revista Jurídica, Porto Alegre: Editora Síntese Ltda., n. 240, p. 5-6, outubro de 1997.

http://revistasapereaude.org/index.php/edicoes/ano-5-volume-4-novembro-2016

D.O.I: $10.20523 /$ sapereaude-ano5-vol-4-pg-40-65 